\title{
Flatness-based Adaptive Control (FBAC) for STATCOM
}

\author{
Yao Xu ${ }^{\mathrm{a}}$, Fangxing $\mathrm{Li}^{\mathrm{a}}{ }^{\mathrm{b}}$, Zhiqiang Jin ${ }^{\mathrm{a}}$ and Can Huang ${ }^{\mathrm{a}}$ \\ a: Dept. of EECS, The University of Tennessee; Knoxville, TN, 37996; USA. \\ b: Contact author: fli6@utk.edu,+1-865-974-8401.
}

Abstract-This paper proposes a new method, called the flatness-based adaptive control (FBAC), for STATCOM voltage regulation. By this method, the nonlinear STATCOM variables can be easily and exactly controlled by controlling flat output without solving differential equations. Further, the control gains can dynamically self-adjust during the voltage regulation after a disturbance. Thus, the performance from FBAC will consistently match a desired response, regardless of the change of operating conditions. In contrast, the traditional PI control and the flatness-based control (FBC), even if well-tuned for a specific given operating condition, may be inefficient or incapable to correct voltage when there is a change of the operating conditions or the STATCOM is deployed in a new power system. The advantage of the proposed FBAC over the original control and FBC control are demonstrated with the simulation studies under different operating conditions, such as a change of network and a change of load.

Keywords - STATCOM, PI control, nonlinear control, flatness-based control (FBC), flatness-based adaptive control (FBAC), voltage stability, reactive power compensation.

\section{Nomenclatures}

$R_{s}=$ Sum of the transformer winding losses and the inverter conduction losses of Figure 1

$L_{s}=$ Transformer leakage inductance of Figure 1

$C=$ Capacitance of the dc side capacitor of Figure 1

$V_{a l}, V_{b l}$, and $V_{c l}=$ Three-phase STATCOM output voltages of Figure 1

$V_{a s}, V_{b s}$, and $V_{c s}=$ Three phase bus voltages of Figure 1

$i_{a s}, i_{b s}$, and $i_{c s}=$ Three-phase currents of Figure 1

$V_{d c}=$ DC-side voltage of Figure 1

$\omega=$ Synchronously rotating angle speed of Eq. (5)

$i_{d s}$ and $i_{q s}=d$ and $q$ axis currents corresponding to $i_{a s}, i_{b s}$, and $i_{c s}$

$V_{d s}$ and $V_{q s}=d$ and $q$ axis voltages corresponding to $V_{a s}, V_{b s}$, and $V_{c s}$

$V_{d l}$ and $V_{q l}=d$ and $q$ axis voltages corresponding to $V_{a l}, V_{b l}$, and $V_{c l}$

$m_{a}=$ Ratio between the peak amplitude of the phase converter voltage to dc voltage 
$\delta=$ STATCOM voltage vector position in the $d$ - $q$ frame

$V_{d c r e f}=$ Reference voltage for $V_{d c}$

$V_{d s r e f}=$ Reference voltage for $V_{d s}$

$i_{d s r e f}=$ Reference current for $i_{d s}$

$i_{q s r e f}=$ Reference current for $i_{q s}$

$x=$ State variable

$u=$ Vector of input variables

$y=$ Flat output

$y_{\text {ref }}=$ Reference flat output for $y$

$\beta=$ Finite numbers of derivative

$K_{11}, K_{21}$ and $K_{22}=$ Control Gains

$t_{0}=$ Time that the initial disturbance occurs

$t_{1}=$ Final time of the dynamic study

$i_{q s}\left(t_{0}\right)$ and $V_{d c}\left(t_{0}\right)=$ Desired initial states of $i_{q s}$ and $V_{d c}$, also are written as $i_{q s}(0)$ and $V_{d c}(0)$

$i_{q s}\left(t_{1}\right)$ and $V_{d c}\left(t_{l}\right)=$ Final states of $i_{q s}$ and $V_{d c}$

$\Delta V_{\max }=$ maximum voltage drop that the STATCOM can support

$\Delta V=$ voltage error between the measured voltage and desired voltage (1.0 p.u.)

$\operatorname{err}_{l}(\mathrm{t})=y_{l}(\mathrm{t})-y_{1 r e f}(\mathrm{t})$

$\operatorname{err}_{2}(\mathrm{t})=y_{2}(\mathrm{t})-y_{2 \operatorname{ref}}(\mathrm{t})$

$e \dot{r} r_{2}(\mathrm{t})=\dot{y}_{2}(\mathrm{t})-\dot{y}_{2 r e f}(\mathrm{t})$.

\section{Introduction}

The Static Compensator (STATCOM) has gained significant popularity for providing dynamic voltage support to power systems over the past decade [1-2]. Various control methods have been applied to STATCOM for dynamical voltage control. Regarding the control strategies, the control of active and reactive components of STATCOM current is normally achieved through proportional-integral (PI) controllers. A typical double-loop control strategy is used in STATCOM [3-4]. The outer loop forms the desired active and reactive current commands to maintain the voltages at the point of common coupling (PCC) and to compensate the STATCOM losses, while the inner loop controls the inverter currents with zero steady-state errors. This control strategy has a coupling relationship between the active current and the reactive current, and thus, it is hard to maintain the voltages at the PCC with small disturbances on the dc-link voltage. To address this challenge, in References [5-8], 
various approaches were proposed to eliminate the coupling effects in the PI controller design.

However, all these PI controller designs are based on control methods which are based on a linearized averaged model of STATCOM. Since the averaged model of STATCOM is nonlinear, model-based nonlinear control methods are proposed in [9-14] to directly compensate the system nonlinearities without the requirement of a linear approximation. Also, a new method, called flatness-based control (FBC), is proposed and applied in STATCOM [15-17].

Flatness is a mathematical property of a system described by a set of differential equations. With FBC, a nonlinear flat system is equivalent to a linear controllable system, and the trajectories of all system variables can be directly estimated by flat output and its derivatives [18-20]. Flat systems are subset of nonlinear systems; in other words, some nonlinear systems may demonstrate the characteristic of flatness. The flatness feature can be utilized for motion planning, trajectory generation, and stabilization. Theoretically, a flat system could be feedback linearized, which is, however, not a better choice than the flat control approach. Further, flatness is a feature independent of coordinate choice which is critical to the linearization in nonlinear control. That is, choosing a different coordinate system may not convert the nonlinear system to a linear one. However, coordinate choice is irrelevant in FBC [25-26].

On the other hand, many previous methods may not be robust to variable system operating conditions. In many previous works the PI controller gains in traditional linearized, averaged model control methods are designed in a case-by-case study or trial-and-error approach [3-5] with trade-offs in performance and efficiency. It is not preferred for utility engineers to perform trial-and-error studies to find suitable parameters when a new STATCOM is connected to a system. To improve this, a variety of controls have been presented in [21-24, 27]. In [21-22], a linear optimal control is proposed based on the linear quadratic regular (LQR) control. Since the gains in LQR control depend on the designer's choice of weighting matrix, the optimal parameters may depend on the designer's experience. In [23-24, 27], a fuzzy PI control method is proposed to tune PI controller gains. The fuzzy control method essentially gives "fuzzy" recommendation and it is still up to the designer to choose the actual, deterministic gains. Therefore, again, the designer's experience may affect the final results.

In the nonlinear control and the FBC [15-17], the control laws with fixed gains are normally designed by trial and error approach or by the pole-placement method. Therefore, these approaches are also either time consuming or affected by the designer's experiences.

Based on the discussion above, the traditional PI control and the FBC with fixed control gains need to be tuned to fit the projected scenarios. It may not perform the same well as initially expected when a considerable 
change of the system condition occurs such as a transmission line is upgraded or retires from service [28-29]. The situation can be even worse if such transmission topology change is due to a contingency. Thus, the STATCOM control system may not perform at its best when mostly needed.

To improve the STATCOM performance and achieve a quick and desirable control under different disturbances in a power system, a flatness-based adaptive control method (FBAC) is proposed and applied to STATCOM for voltage control in this paper. By FBC, the trajectories of all system variables can be directly estimated by flat output and its derivatives without solving differential equations. By adaptive control, the control gains can be dynamically tuned to satisfy the time-varying operation condition requirement. Different from other control methods, the proposed control method avoids the coupling effects between the active current and the reactive current. Also this control method is robust to various system operating conditions and will not be affected by the limits of human experience and judgment. Even if the system operation condition has a drastic change, the FBAC can consistently achieve a fast, dynamic performance of STATCOM.

This paper is organized as follows. Section 3 illustrates system configuration and the STATCOM dynamic model. Section 4 presents the FBAC with theoretical analysis. Section 5 compares the traditional PI control (called original control in the paper), the FBC and the proposed FBAC, and presents the simulation results. Finally, Section 6 provides a conclusion and possible future work.

\section{STATCOM Model and Control}

The equivalent circuit of the STATCOM is shown in Figure 1. In this power system, the equivalent connecting impedance consists of $R_{s}$ and $L_{s}$ in series with the voltage source inverter [4-6, 21].

The three-phase mathematical expressions of the STATCOM can be written in the following form:

$$
\begin{aligned}
& L_{s} \frac{d i_{a s}}{d t}=-R_{s} i_{a s}+V_{a s}-V_{a l} \\
& L_{s} \frac{d i_{b s}}{d t}=-R_{s} i_{b s}+V_{b s}-V_{b l} \\
& L_{s} \frac{d i_{c s}}{d t}=-R_{s} i_{c s}+V_{c s}-V_{c l} \\
& \frac{d}{d t}\left(\frac{1}{2} C V_{d c}^{2}(t)\right)=\left[V_{a l} i_{a s}+V_{b l} i_{b s}+V_{c l} i_{c s}\right]
\end{aligned}
$$

By using the abc/dq transformation, the equations from (1) to (4) can be rewritten as:

$$
\begin{aligned}
& \left\{\begin{array}{c}
L_{s} \frac{d i_{d s}}{d t}=-R_{s} i_{d s}+\omega L_{s} i_{q s}+V_{d s}-V_{d l} \\
L_{s} \frac{d i_{q s}}{d t}=-R_{s} i_{q s}-\omega L_{s} i_{d s}+V_{q s}-V_{q l} \\
\frac{d}{d t}\left(\frac{1}{2} C V_{d c}^{2}\right)=\frac{3}{2}\left(V_{d l} i_{d s}+V_{q l} i_{q s}\right)
\end{array}\right. \\
& V_{d l}=\frac{1}{2} V_{d c} m_{\alpha} \cos \delta \\
& V_{q l}=\frac{1}{2} V_{d c} m_{\alpha} \sin \delta
\end{aligned}
$$

Based on the above equations, the traditional control strategy can be obtained, and the STATCOM control block diagram is shown in Figure $2[4,7]$. 
In Figure 2, a typical double-loop control strategy is used in STATCOM. The traditional PI control with fixed control gains may not satisfy the requirements of the changeable power system operation conditions. Moreover, this control system has a coupling relationship between the active current and the reactive current, and thus, it is hard to maintain the voltages at the PCC with small effects on the dc-link voltage. These are potential difficulties for a large-scale utilization of STATCOM. Therefore, the flatness-based adaptive control (FBAC) method is proposed to avoid the effects of the coupling and obtain the desired response during the variable system operation condition in Section 4.

\section{Flatness-Based Adaptive Control for STATCOM}

\subsection{Brief Introduction of Flatness-based Control}

Consider a general nonlinear system of the form:

$$
\begin{aligned}
& \dot{x}=f(x)+g(x) u \\
& x=\left[x_{1}, x_{2}, \ldots x_{n}\right]^{T} \quad x \in R^{n} \\
& u=\left[u_{1}, u_{2}, \ldots u_{m}\right]^{T} \quad u \in R^{m}
\end{aligned}
$$

If the state variable $x$ can be parameterized by output $y$ and its derivatives, the system is said to be differentially flat and admits the flat output $y=\left[y_{1}, y_{2}, \ldots, y_{m}\right]^{T}[18-20]$. Then, the state variables and control variables can be written as follows:

$$
\begin{aligned}
& x=\phi\left(y, \dot{y}, \ldots, y^{(\beta)}\right) \\
& u=\phi\left(y, \dot{y}, \ldots, y^{(\beta+1)}\right)
\end{aligned}
$$

By this process, a nonlinear flat system can be equivalent to a linear controllable system as described in References [18-20], where more details of flatness-based control (FBC) can be found.

\subsection{FBC Design for STATCOM}

To realize FBC in STATCOM, we set the state variable as: $x=\left(x_{1}, x_{2}, x_{3}\right)^{T}=\left(i_{d s}, i_{q s}, V_{d c}\right)^{T}$, and the input control variable as: $u=\left(u_{1}, u_{2}\right)^{T}=\left(m_{a} \cos \delta, m_{a} \sin \delta\right)^{T}$. Neglecting the inductance and converter losses and the change in the energy stored in the inductance [11-12], we can rewrite (5) in standard form $\dot{x}=f(x)+g(x) u$ as follows:

$$
\left\{\begin{array}{c}
\dot{x}_{1}=-\frac{R_{s}}{L_{s}} x_{1}+\omega x_{2}+\frac{V_{d s}}{L_{s}}-\frac{x_{3} u_{1}}{2 L_{s}} \\
\dot{x}_{2}=-\frac{R_{s}}{L_{s}} x_{2}-\omega x_{1}+\frac{V_{q s}}{L_{s}}-\frac{x_{3} u_{2}}{2 L_{s}} \\
\dot{x}_{3}=\frac{3}{2 C x_{3}}\left(x_{1} V_{d s}\right)
\end{array}\right.
$$

Since all system variables can be determined if we know $i_{q s}$ and $V_{d c}$. Therefore, the flat output in this system can be set as: 


$$
\left\{\begin{array}{l}
y_{1}=x_{2} \\
y_{2}=x_{3}
\end{array}\right.
$$

Based on (13) and (14), the following equation can be derived:

$$
\left\{\begin{array}{c}
\dot{y}_{1}=\dot{x}_{2} \\
\dot{y}_{2}=\dot{x}_{3} \\
\ddot{y}_{2}=\frac{3\left(\dot{x}_{1} x_{3} V_{d s}-\dot{x}_{3} x_{1} V_{d s}\right)}{2 C x_{3}^{2}}
\end{array}\right.
$$

Based on (13)-(15), using $y$ and $y$ 's derivative to express $x=\left(x_{1}, x_{2}, x_{3}\right)^{T}$ and $u=\left(u_{1}, u_{2}\right)^{T}$, we have:

$$
\begin{aligned}
& \left\{\begin{array}{c}
x_{1}=\frac{2 C}{3 V_{d s}} \dot{y}_{2} y_{2} \\
x_{2}=y_{1} \\
x_{3}=y_{2}
\end{array}\right. \\
& \left\{\begin{array}{c}
u_{1}=\frac{2}{y_{2}}\left(-L_{S} \frac{2 C}{3 V_{d s}}\left(y_{2} \ddot{y}_{2}+\dot{y}_{2}^{2}\right)+\omega L_{S} y_{1}-R_{S} \frac{2 C}{3 V_{d s}} y_{2} \dot{y}_{2}+V_{d s}\right) \\
u_{2}=\frac{2}{y_{2}}\left(-L_{S} \dot{y}_{1}-\omega L_{S} \frac{2 C}{3 V_{d s}} y_{2} \dot{y}_{2}-R_{S} y_{1}+V_{q s}\right)
\end{array}\right.
\end{aligned}
$$

Then the following equations can be obtained as (18) and (19).

$$
\begin{aligned}
& \mathrm{m}_{a}=\sqrt{u_{1}^{2}+u_{2}^{2}} \\
& \delta=\arctan \frac{u_{2}}{u_{1}}
\end{aligned}
$$

Based on (13)-(19), the FBC can be implemented with the control block shown in Figure 3.

In Figure 3, $y_{1 r e f}$ and $y_{2 r e f}$ are defined by the system desired initial and final conditions. As shown in Figure 3, the nonlinear STATCOM system can be equivalent to a linear system, and the trajectories of all system variables can be directly estimated by flat output and its derivatives without solving differential equations. This is the advantage of FBC when applied to STATCOM control.

\subsection{Flat Output}

The initial and final conditions are modelled as follows:

$$
\begin{gathered}
\left\{\begin{array}{l}
y_{1 \text { ref }}\left(t_{0}\right)=I_{q s}\left(t_{0}\right) \\
y_{1 \text { ref }}\left(t_{1}\right)=I_{q s}\left(t_{1}\right) \\
y_{2 \text { ref }}\left(t_{0}\right)=V_{d c}\left(t_{0}\right) \\
y_{2 \text { ref }}\left(t_{1}\right)=V_{d c}\left(t_{1}\right)
\end{array}\right. \\
\left\{\begin{array}{l}
\dot{y}_{1 \text { ref }}\left(t_{0}\right)=0 \\
\dot{y}_{1 \text { ref }}\left(t_{1}\right)=0 \\
\dot{y}_{2 \text { ref }}\left(t_{0}\right)=0 \\
\dot{y}_{2 \text { ref }}\left(t_{1}\right)=0 \\
\ddot{y}_{2 \text { ref }}\left(t_{0}\right)=0 \\
\ddot{y}_{2 \text { ref }}\left(t_{0}\right)=0
\end{array}\right.
\end{gathered}
$$

In order to satisfy Eqs. (20) and (21), the desired trajectory for flat output can be expressed as:

(1) $0<t<t_{0}$

$$
\left\{\begin{array}{l}
y_{1 r e f}(t)=I_{q s}(0) \\
y_{2 r e f}(t)=V_{d c}(0)
\end{array}\right.
$$

(2) $t_{0} \leq t \leq t_{1}$ 


$$
\left\{\begin{array}{c}
y_{1 r e f}(t)=I_{q s}(0)+\left(I_{q s}\left(t_{1}\right)-I_{q s}(0)\right) \times d d_{1} \\
y_{2 r e f}(t)=V_{d c}(0)+\left(V_{d c}\left(t_{1}\right)-V_{d c}(0)\right) \times d d_{2}
\end{array}\right.
$$

Without losing generality, in order to make the output curve as smooth as possible, we may set

$$
\left\{\begin{array}{l}
y_{1 \text { ref }}(t)=\sum_{j=0}^{N} \frac{a_{j}}{j !}\left(t-t_{0}\right)^{j} \\
y_{2 \text { ref }}(t)=\sum_{j=0}^{N} \frac{b_{j}}{j !}\left(t-t_{0}\right)^{j}
\end{array}\right.
$$

Based on (20) and (21), $d d_{l}$ and $d d_{2}$ can be obtained as follows:

$$
\left\{\begin{array}{c}
\mathrm{dd}_{1}=\left(4 \times\left(\frac{\mathrm{t}-\mathrm{t}_{0}}{\mathrm{t}_{1}-\mathrm{t}_{0}}\right)^{2}-4 \times\left(\frac{\mathrm{t}-\mathrm{t}_{0}}{\mathrm{t}_{1}-\mathrm{t}_{0}}\right)^{3}+\left(\frac{\mathrm{t}-\mathrm{t}_{0}}{\mathrm{t}_{1}-\mathrm{t}_{0}}\right)^{4}\right) \\
\mathrm{dd}_{2}=\left(9 \times\left(\frac{\mathrm{t}-\mathrm{t}_{0}}{\mathrm{t}_{1}-\mathrm{t}_{0}}\right)^{3}-12 \times\left(\frac{\mathrm{t}-\mathrm{t}_{0}}{\mathrm{t}_{1}-\mathrm{t}_{0}}\right)^{4}+3 \times\left(\frac{\mathrm{t}-\mathrm{t}_{0}}{\mathrm{t}_{1}-\mathrm{t}_{0}}\right)^{5}+\left(\frac{\mathrm{t}-\mathrm{t}_{0}}{\mathrm{t}_{1}-\mathrm{t}_{0}}\right)^{6}\right)
\end{array}\right.
$$

(3) $t>t_{1}$

$$
\left\{\begin{array}{l}
y_{1 \text { ref }}(t)=I_{q s}\left(t_{1}\right) \\
y_{2 \text { ref }}(t)=V_{d c}\left(t_{1}\right)
\end{array}\right.
$$

\subsection{Control Law for Flatness-based Adaptive Control}

The differential parameterization of the control input $u=\left(u_{1}, u_{2}\right)^{T}$ can be expressed by $\left(y_{1}, y_{2}, \dot{y}_{1}, \dot{y}_{2}, \ddot{y}_{2}\right)^{T}$. Also, the proposed flat output trajectory tracking is to control $\dot{y}_{1}$ and $\ddot{y}_{2}$. This can be accomplished by the following linear feedback control law:

$$
\left\{\begin{array}{c}
\dot{y}_{1}=\dot{y}_{1 r e f}-\left(y_{1}-y_{1 r e f}\right) K_{11} \\
\ddot{y}_{2}=\ddot{y}_{2 r e f}-K_{11}\left(\dot{y}_{2}-\dot{y}_{2 r e f}\right)+K_{21}\left(y_{2}-y_{2 r e f}\right)
\end{array}\right.
$$

In the previous work [19], the choice of the coefficients $K_{11}, K_{21}$ and $K_{22}$ is to guarantee the satisfaction of the Hurwitz polynomial condition (namely, to guarantee that the roots are located in the left part of the complex plane). Thus, the asymptotic exponential stability to zero of the tracking error is guaranteed.

However, the constant gains cannot ensure an optimized and consistently efficient performance for various external conditions. In order to achieve a control method that can ensure a fast and desirable response when the system operation condition varies, an adaptive control scheme is combined with flat control. Here, the flat control gains are dynamically and adaptively adjusted based on the external condition. Thus, the proposed control method is termed flatness-based adaptive control (FBAC).

The process of adaptive control design is described as follows with different scenarios of the error value. Based on the system bus capacity and the STATCOM rating, $\Delta V_{\max }$ can be obtained, which means any voltage change greater than $\Delta V_{\max }$ cannot come back to 1 per unit. Based on [3], the sensitivity of $d i_{q s} / d V$ is around 1 p.u. $/ 0.034$ p.u. of voltage in this paper. For simplicity, we may assume the $\Delta i_{q s} / \Delta V$ sensitivity is a linear function. 
When the voltage error is $\varepsilon_{2}=0.0001$ p.u., $\Delta i_{q s}$ is $\varepsilon_{1}=0.003$ p.u.. If the system voltage error is less than $\varepsilon_{2}$ p.u., the system is considered as stable and control gains are kept the same. Otherwise, the control gains need to be tuned to make system voltage get back to 1 p.u.. Since $y_{l}=i_{q s}, e r r_{1}$ is considered. If $\left|e r r_{1}(t)\right|<\varepsilon_{1}$, the system is considered as stable, and $K_{11}(t)$ can be set as initial values (such as 1). If $\left|e r r_{1}(t)\right|>\varepsilon_{1}$, the following approach is employed to tune control gains.

(1) When $0<t<t_{0}: y_{\text {lref }}(0) \neq 0$ and $y_{1}(t)$ needs to be increased to $y_{\text {lref }}(t)$ as quickly as possible (i.e., in one sampling cycle $\Delta t$ ) to ensure $\operatorname{err}_{l}=0$. Without losing of generality, we can assume $y_{l}(t)=y_{1 r e f}(t)$ after $\Delta t$. Thus, we have $\mathrm{K}_{11}(t)=\frac{1}{\Delta t}$.

(2) When $t_{0} \leq \mathrm{t} \leq t_{1}$ : since the final ideal state $\dot{y}_{1}(t)=0$, based on (22), we can obtain:

$$
0=\dot{y}_{1 r e f}(t)-\left(y_{1}(t)-y_{1 r e f}(t)\right) K_{11}(t)
$$

Therefore:

$$
\mathrm{K}_{11}(t)=\left|\frac{\dot{y}_{1 r e f}(t)}{\operatorname{err}_{1}(t)}\right|
$$

(3) When $t>t_{1}: y_{l}(t)$ needs to be increased to $y_{1 r e f}(t)$ as quickly as possible to ensure $e r r_{l}=0$. Since we consider $y_{1}(t)=y_{\text {lref }}(t)$ after $\Delta t$, we have $\mathrm{K}_{11}(t)=\frac{1}{\Delta t}$

Next, $\operatorname{err}_{2}(t)$ is considered in a similar yet different way. Based on [3], $\Delta V_{d c}$ and the system voltage error are in the same range. Therefore, If $\left|\operatorname{err}_{2}(t)\right|<\varepsilon_{2}, K_{21}(t)$ and $K_{22}(t)$ can be set as initial values (such as 1 ). If $\left|\operatorname{err}_{2}(t)\right|>\varepsilon_{2}$, the following approach is employed to tune control gains.

(1) In the ideal state, $\ddot{\mathrm{y}}_{2}(t)=\ddot{\mathrm{y}}_{2 r e f}(t)$. Without losing generality, we can set $K_{22}(t)=K(t) K_{21}(t)$. Then, we have $\mathrm{K}(\mathrm{t})=\left|\frac{\operatorname{err}_{2}(t)}{\operatorname{err} r_{2}(t)}\right|$.

(2) When $0<t<t_{0}$ or $\mathrm{t}>t_{1}: \ddot{\mathrm{y}}_{2}(t)$ needs to be decreased to $\ddot{y}_{2 r e f}(t)$ as quickly as possible (i.e., in one sampling cycle $\Delta t$ ) to ensure $\operatorname{err}_{2}=0$. Therefore, we have $K_{21}(t)=\left|\frac{e \dot{r} r_{2}(t) / \Delta t}{e r r_{2}(t)+K(t) e \dot{r} r_{2}(t)}\right|$ and $K_{22}(t)=$ $\mathrm{K}(\mathrm{t})\left|\frac{e \dot{r} r_{2}(t) / \Delta t}{e r r_{2}(t)+K(t) e \dot{r} r_{2}(t)}\right|$.

(3) When $t_{0} \leq \mathrm{t} \leq t_{1}$ : the ideal state $\ddot{\mathrm{y}}_{2}(t)=0$. Set $t t=t$ - $\Delta t$, and in a very short time control gains stay the same, such as $K_{21}(t)=K_{21}(t t)$ and $K_{22}(t)=K_{22}(t t)$. if the system stable, we have:

$$
\begin{gathered}
0=\ddot{y}_{2 r e f}(t)-K_{22}(t) e \dot{r} r_{2}(t)-K_{21}(t) e r r_{2}(t) \\
0=\ddot{y}_{2 r e f}(t t)-K_{22}(t) e \dot{r} r_{2}(t t)-K_{21}(t) e r r_{2}(t t)
\end{gathered}
$$

Based on (24) and (25), the following equation can be obtained: 


$$
\begin{gathered}
K(t)=\left|\frac{\ddot{y}_{2 r e f}(t) e r r_{2}(t t)-\ddot{y}_{2 r e f}(t t) e r r_{2}(t)}{e \dot{r} r_{2}(t) \ddot{y}_{2 r e f}(t t)-e \dot{r} r_{2}(t t) \ddot{y}_{2 r e f}(t)}\right| \\
K_{21}(t)=\left|\frac{\ddot{y}_{2 r e f}(t)}{e r r_{2}(t)+K(t) e \dot{r} r_{2}(t)}\right| \\
K_{22}(t)=K(t) K_{21}(t)
\end{gathered}
$$

Based on the proposed control law, the FBAC can be implemented as shown in Figure 4. This module is the "Control Law" block in Figure 3 which shows the FBAC diagram.

Based on the FBC logic and the adaptive control module shown in Figures 3 and 4, respectively, the FBAC can be designed and implemented. Next, in Section 5, the simulation results from the original control (Section 3), the FBC (Subsection 4.2) and the FBAC (combination of Subsections 4.2, 4.3 and 4.4) will be discussed and compared.

\section{Simulation Results}

\subsection{System Data}

In the system simulation diagram shown in Figure 5, the STATCOM is connected at Bus B2 on a $500 \mathrm{kV}$ transmission line. The power grid consists of two $500 \mathrm{kV}$ equivalents (3000 MVA and $2500 \mathrm{MVA}$, respectively) connected by a 600-kilometer transmission line. In this study system, the STATCOM has a rating of +/- 100MVA. It is a phasor model of a typical three-level PWM STATCOM. DC link nominal voltage is $40 \mathrm{kV}$ with an equivalent capacitance of $375 \mathrm{uF}$. The transformer leakage reactance and the phase reactor of the IGBT bridge of an actual PWM STATCOM are 0.22 p.u. on 100 MVA in this system. The PI parameters for reactive voltage controller, the DC voltage controller and the current controller are [5, 1000], [0.0001, 0.02] and [0.3, 10], respectively. Structure of the proposed control method implemented in Simulink is shown in Figure 5. All these data can also be found in [3].

In the original model, the control system is realized by four PI controllers and referred to as the original control in this section. Note, the original control gains shown in literature [3] are well tuned. In the flatness-based control (FBC), which is elaborated in Subsection 4.2, the control gains $K_{11}, K_{21}$ and $K_{22}$ are also well tuned based on the trial and error approach for the first case study (i.e., Subsection 5.2 below) and are set at 1.6, 0.9 and 0.9, respectively. In the proposed flatness-based adaptive control (FBAC), which is a combined model of Subsections 4.2, 4.3, and 4.4, the initial control gains are set to 1's, and then the gains are dynamically adjusted based on the method described in Subsection 4.4. The original control, the FBC and the FBAC are compared in this section. In the simulation, the reference voltage at Bus B2, shown in Figure 5, is $1.0 \mathrm{p}$. u. at the beginning, with the voltage base being $500 \mathrm{kV}$. Assume the initial disturbance occurs at $t_{0}=0.2 \mathrm{sec}$; and the system is expected to reach back 
the desired normal state at $t_{l}=0.3 \mathrm{sec}$.

\subsection{Change of Reactive Load}

Here, we keep all the parameters unchanged, as in the original studied system. At $t_{0}=0.2 \mathrm{sec}$, a new reactive load of 80 MVar is added at B2 as a disturbance. The results of Bus B2 voltage (V), STATCOM reactive power output (Q), the d and q axis currents are shown in Figure 6 (a) to (d) respectively. Observations are summarized in Table 1.

From the results, it is obvious that the FBC and the proposed FBAC can achieve quicker response than the original control. The needed reactive power, $i_{d s}$, and $i_{q s}$ are the same while the FBC and the FBAC perform much faster to bring the voltage back to 1.0 . Note, as previously mentioned, the control gains $K_{11}, K_{21}$ and $K_{22}$ in the FBC are well tuned based on this case using the trial and error approach and are set at 1.6, 0.9 and 0.9, respectively. Since the parameters are well tuned for this case, the FBC can give desirable responses very close to the response of the proposed FBAC in this case.

\subsection{Change of Transmission Network}

In this case, the original system parameters are kept. However, a new Line L3 of $125 \mathrm{~km}$ is added between bus B2 and B3 at the system to mimic a new operation topology. Then, Line L3 is switched off at $t_{0}=0.2 \mathrm{sec}$ to mimic a disturbance. The results from the original control, the FBC and the proposed FBAC are shown in Figure 7. Observations are summarized in Table 2.

From the results, we can find out that when the transmission network changes, the original control and the FBC cannot bring the system voltage back to 1 p.u. even during the initialization stage before the disturbance occurs at $0.2 \mathrm{sec}$. This also implies that the gains in the original PI control and FBC must be manually re-turned to achieve a satisfying performance under a new topology.

After the disturbance (switching off Line L3) occurs at $0.2 \mathrm{sec}$, the FBC cannot make the system reach its steady-state voltage within $0.6 \mathrm{sec}$. Note, a separate diagram in Figure 7(e) with extended simulation time shows that the voltage eventually reaches back to 1 p.u. at $t=2.2863 \mathrm{sec}$, or $2.0863 \mathrm{sec}$ after the disturbance of topology change. This is also shown in Table II. The original control performs better, reaching 1.0 p.u. in 0.1824 sec after the topology change. However, this is still much slower than the proposed FBAC which brings the system voltage back to 1 p.u. in $0.0914 \mathrm{sec}$ after the disturbance, as shown in Table 2.

The response time (i.e., $\Delta \mathrm{t}$ to reach $\mathrm{V}=1.0$ ) of the FBAC is only $50 \%$ of the original control and $4.3 \%$ of the FBC. In other words, the FBAC shortens the response time by $0.1 \mathrm{sec}$ and $2.0 \mathrm{sec}$ respectively, as opposed to the 
original control and the FBC. Since $0.1 \mathrm{sec}$ can be significant in modern STATCOM control and makes a big difference in STATCOM performance [21], the improved performance with FBAC is considerable. Therefore, the proposed FBAC can achieve a response quicker than the original control and even much quicker than the FBC. Thus, the control gains $K_{11}, K_{21}$ and $K_{22}$ in the original control and the FBC are not optimal under this new topology. Some form of gain tuning of $K_{11}, K_{21}$ and $K_{22}$ must be performed to achieve the same response as the proposed FBAC. Apparently, the tuning-free FBAC has an advantage over the other two controls.

\subsection{Change of Transmission Network and Load}

In this case, the original system parameters are kept. However, a $125 \mathrm{~km}$ new Line L3 is added between bus B2 and B3 at the system to mimic the new operation system. Line 1 is switched off and a new load 200MW is added at B2 at $0.2 \mathrm{sec}$ as a large disturbance. The results of three controls are shown in Figure 8. Again, it should be noted that the initial dynamics in these figures are due to the change of transmission network. Observations are summarized in Table 3.

From the results, the FBAC response remains unchanged under this disturbance, while the original control method gives slower response and the FBC cannot bring the voltage back to steady-state in 0.6 sec. Note, a separate diagram in Figure 8(e) with extended simulation time shows that the voltage eventually reaches back to 1 p.u. at $t=1.9082 \mathrm{sec}$, or $1.7082 \mathrm{sec}$ after the disturbance. This is also shown in Table III.

The observation is similar to the previous case. The response time (i.e., $\Delta \mathrm{t}$ to reach $\mathrm{V}=1.0$ ) of the FBAC is only $47 \%$ of the original control and $6 \%$ of the FBC. Hence, similar to the previous case, the advantage of the proposed FBAC method is clearly demonstrated again.

\subsection{Summary of simulation study}

The three case studies in Subsections 5.2 to 5.4 show the advantage of the proposed FBAC over the original control and the FBC. The original control and the FBC models may have a desirable response in a specific system. However, when system operating condition changes, the FBC gains and tradition PI control gains need to be redesigned or re-tuned to obtain satisfying responses; otherwise, the original control and the FBC may be subject to slower response, as demonstrated in Subsections 5.3 and 5.4. In contrast, the proposed FBAC can consistently achieve fast, smooth, and desirable responses under various changes of system operating conditions such as a change of load and a change of network, and the response curves are almost identical in all cases. Thus, it achieves the tuning-free and plug-and-play characteristic.

Note, for different system operation condition, the flat output references will be defined based on Eqs. (20) 
and (21), which are based on the measurement and do not require the parameters of the actual system. By controlling the flat output, the system variables can be controlled. Since the proposed flatness based adaptive control can make the flat output always track the reference curve (flat output references), the system can always achieve the steady state voltage after a disturbance as long as the required reactive power stays within the capacity limit of the STATCOM.

\section{Conclusion and Future Work}

This paper proposes the flatness-based adaptive control (FBAC) method for STATCOM voltage regulation. By this method, the effect of the coupling is eliminated. The nonlinear STATCOM system is equivalent to a linear system, and the trajectories of all system variables can be directly and easily controlled by controlling flat output and its derivatives without solving differential equations. Further, the control gains can dynamically self-adjust during the voltage regulation after a disturbance. Thus, the performance from the FBAC always gives a consistent match to a desired response, regardless of the change of operating conditions. However, the original PI control and the flatness-based control (FBC), even if well-tuned for a few given operating conditions, may be inefficient to correct voltage when there is a change of the operating conditions or the STATCOM is deployed in a new power system.

Future work may lie in the investigation of the FBAC applied to other areas such as wind turbine control.

\section{Acknowledgement}

The authors would like to thank the financial support by Stanford University - GCEP project. This work also made use of the Shared Facilities and was supported by the Industry Partnership Program of CURENT, an Engineering Research Centre (ERC) Program of the U.S. National Science Foundation and Department of Energy.

\section{References}

[1] F. Li, J. D. Kueck, D. T. Rizy, T. King, 2006, “A preliminary analysis of the economics of using distributed energy as a source of reactive power supply," Oak Ridge National Laboratory (ORNL) Technical Report (ORNL/TM-2006/014), Oak Ridge, TN, April 2006.

[2] B. Singh, R. Saha, A. Chandra, and K. Al-Haddad, "Static synchronous compensators (STATCOM): A review," IET Power Electron., vol. 2, no. 4, pp. 297-324, 2009.

[3] http://www.mathworks.com/help/physmod/powersys/examples/statcom-phasor-model.html, last access in Apr. 2014. 
[4] C. Schauder and H. Mehta, "Vector analysis and control of the advanced static VAr compensators," Proc. Inst. Elect. Eng., Gen., Transm., Distrib., vol. 140, no. 4, pp. 299-306, Jul. 1993.

[5] I. Papic, P. Zunko, and D. Povh, "Basic control of unified power flow controller," IEEE Trans. Power Syst., vol. 12, pp. 1734-1739, Nov. 1997.

[6] Wei Ren, Lewei Qian, David Cartes, Michael Steurer, "A Multivariable Control Method in STATCOM Application for Performance Improvement," Industry Applications Conference, Fortieth IAS Annual Meeting, 2005 vol 3, 2-6 Oct. 2005 pp.2246 - 2250.

[7] An Luo, Ci Tang, Zhikang Shuai, Jie Tang, Xian Yong Xu, and Dong Chen, "Fuzzy-PI-Based Direct-Output-Voltage Control Strategy for the STATCOM Used in Utility Distribution Systems, ” IEEE Trans. Ind. Electron., vol. 56, no. 1, pp 2401-2411, July 2009.

[8] V. Blasko, V. Kaura, “A New Mathematical Model and Control of a Three-Phase AC-DC Voltage Source Converter," IEEE Trans. Power Electron. , vol. 12, no. 1, Jan 1997

[9] A. Gensior, H. Sira-Ramírez, J. Rudolph, and H. Güldner, "On some nonlinear current controllers for three-phase boost rectifiers," IEEE Trans. Ind. Electron., vol. 56, no. 2, pp. 360-370, Feb. 2009.

[10] N.C. Sahoo, B.K. Panigrahi, P.K. Dash, G. Panda, Application of a multivariable feedback linearization scheme for STATCOM control, Electric Power Syst. Res. vol. 62, no.1, pp.81-91, 2002.

[11] L.H. Gu and J. Wang, "Nonlinear coordinated of excitation and STATCOM of power systems," Electric Power Systems Research, vol. 34, pp. 1-5, 2007.

[12] S.A. Al-Baiyat, Power system transient stability enhancement by STATCOM with nonlinear $H \infty$ stabilizer, Electric Power Systems Research. vol.73, pp. 45-52, 2005.

[13] D. Soto and R. Pena, "Nonlinear control strategies for cascaded multilevel STATCOMs," IEEE Trans. Power Del., vol. 19, no. 4, pp. 1919-1927, Oct. 2004.

[14] Keyou Wang, and Mariesa L. Crow, "Power System Voltage Regulation via STATCOM Internal Nonlinear Control," IEEE Trans. Power Syst., vol. 26, no. 3, pp.1252-1262, Aug. 2011.

[15] E. Song, Experimental validation of a flatness-based control for a voltage source converter, M.S. thesis, Dept. Elect. Comput. Eng., Univ. Alberta, Edmonton, AB, Canada, 2006.

[16] E. Song, A. F. Lynch, and V. Dinavahi, "Experimental validation of nonlinear control for a voltage source converter," IEEE Trans. Control Syst. Technol., vol. 17, no. 5, pp. 1135-1144, Sep. 2009.

[17] A. Gensior, J. Rudolph, and H. Güldner, "Flatness based control of three-phase boost rectifiers," 11th Eur. Conf. Power Electron. Appl. Rec. (EPE), Dresden, Germany, Sep. 2005. 
[18] M. Fliess, J. Lévine, P. Martin, and P. Rouchon, "Flatness and defect of non-linear systems: Introductory theory and applications," Int. J. Control, vol. 61, pp. 1327-1361, 1995.

[19] H. Sira Ramírez and S. K. Agrawal, Differentially Flat Systems. New York: Marcel Dekker, 2004.

[20] P. Thounthong, S. Pierfederici, and B. Davat, "Analysis of differential flatness-based control for a fuel cell hybrid power source," IEEE Trans. Energy Convers., vol. 25, no. 3, pp. 909-920, Sep. 2010.

[21] Pranesh Rao, M. L. Crow, and Zhiping Yang, "STATCOM Control for Power System Voltage Control Applications," IEEE Trans. Power Del., vol. 15, no.4, pp.1311-1317, Oct. 2000.

[22] W. L. Chen and Y. Y. Hsu, "Controller design for an induction generator driven by a variable speed wind turbine," IEEE Trans. Energy Convers., vol. 21, no. 3, pp. 625-635, Sep. 2006.

[23] S. Morris, P.K. Dash, K.P. Basu, A fuzzy variable structure controller for STATCOM, Electric Power Syst. Res. vol.65, no.1, pp.23-34, 2003.

[24] L. O. Mak, Y. X. Ni, and C. M. Shen, "STATCOM with fuzzy controllers for interconnected power systems," Elect. Power Syst. Res., vol. 55, pp. 87-95, 2000.

[25] P. Martin, R. M. Murray, and P. Rouchon, "Flat systems, equivalence and trajectory generation," Ecole des Mines de Paris, Technical report, April 2003.

[26] M. van Nieuwstadt and R. Murray. "Real-time trajectory generation for differentially at systems." Int. Journal of Robust and Nonlinear Control, 8(11):995-1020, 1998.

[27] V. Bano, A. Ramirez, M. Juan, "DStatCom regulation by a fuzzy segmented PI controller", Electric Power Systems Research, vol. 80, no. 6, pp 707-715, June 2010.

[28] H. Li, F. Li, J. D. Kueck, and D. T. Rizy “Adaptive Voltage Control with Distributed Energy Resources: Algorithm, Theoretical Analysis, Simulation and Field Test Verification," IEEE Transactions on Power Systems, vol. 25, no. 3, pp. 1638-1647, August 2010.

[29] H. Li, F. Li, Y. Xu, D.T. Rizy and S. Adhikari, "Autonomous and Adaptive Voltage Control using Multiple Distributed Energy Resources," IEEE Transactions on Power Systems, vol. 28, no. 2, pp. 718-730, May 2013. 
Figure 1: Equivalent circuit of STATCOM

Figure 2: Traditional STATCOM PI control block diagram

Figure 3: Flatness-based control (FBC) block

Figure 4: Implementation of the adaptive control module

Figure 5: The test system for simulation study

Figure 6: Results for change of reactive load

Figure 7: Results for change of transmission network

Figure 8: Results for change of transmission network and load 


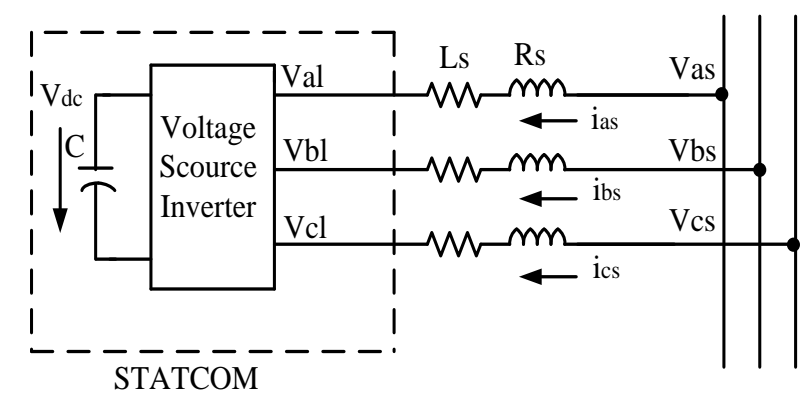

Figure 1: Equivalent circuit of STATCOM

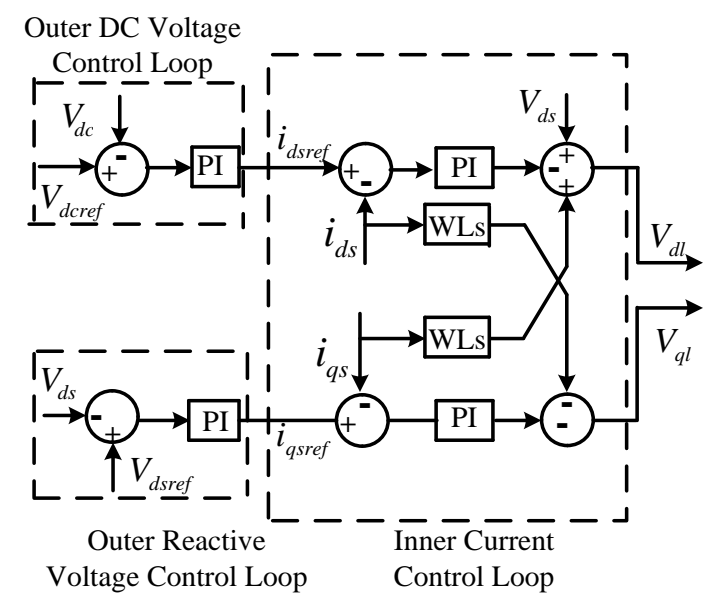

Figure 2: Traditional STATCOM PI control block diagram

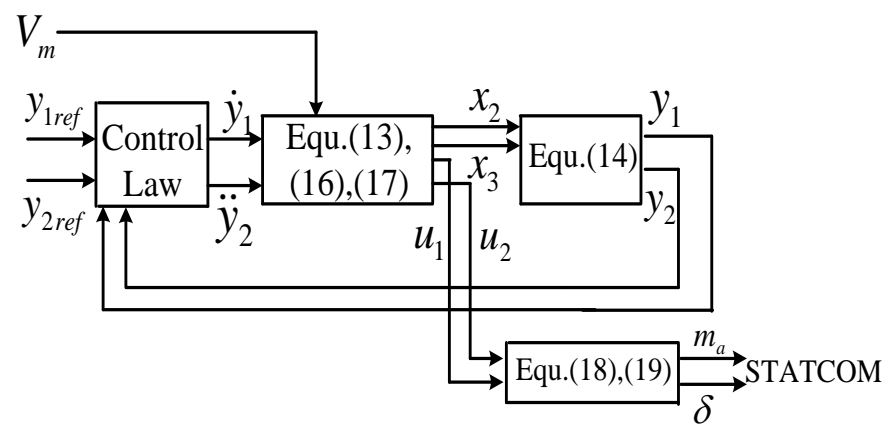

Figure 3: Flatness-based control (FBC) block 

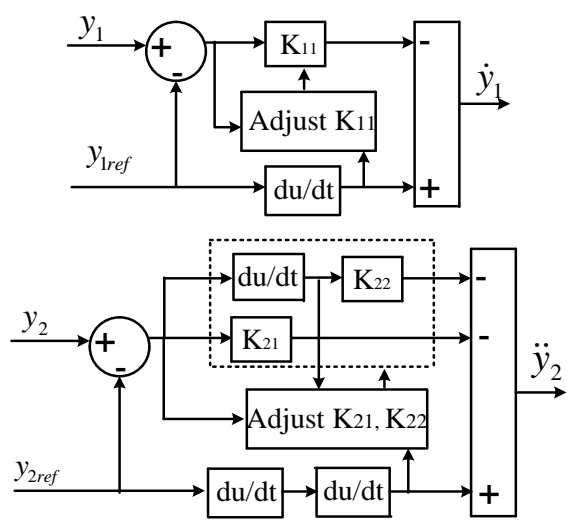

Figure 4: Implementation of the adaptive control module

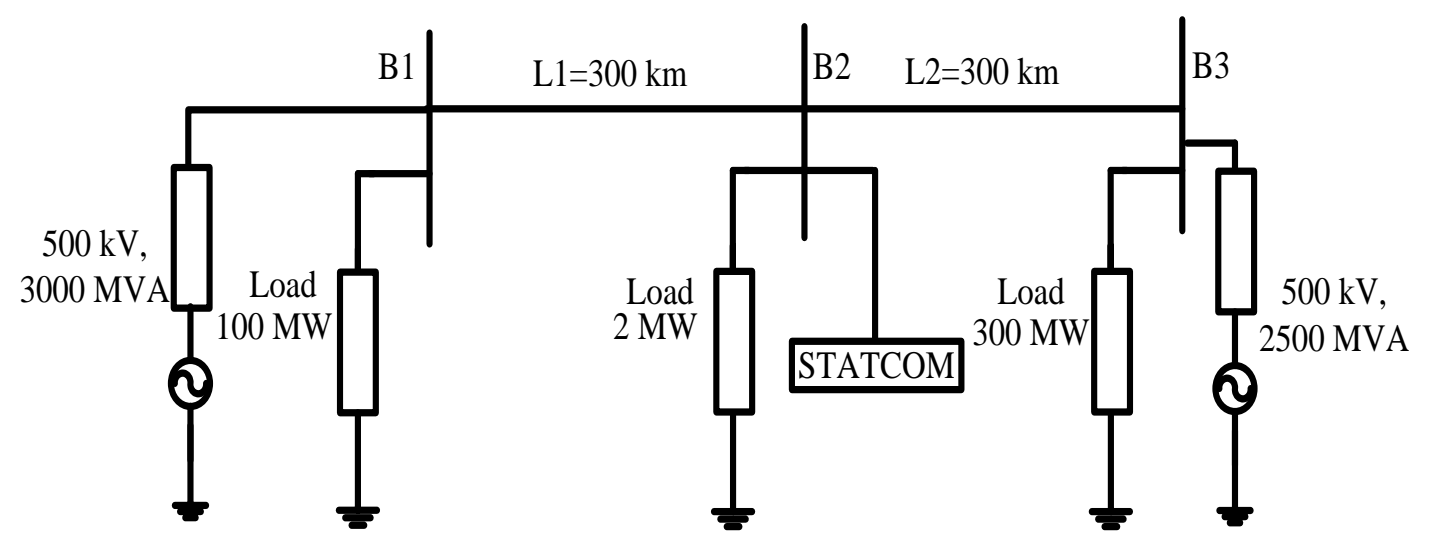

Figure 5: The test system for simulation study 

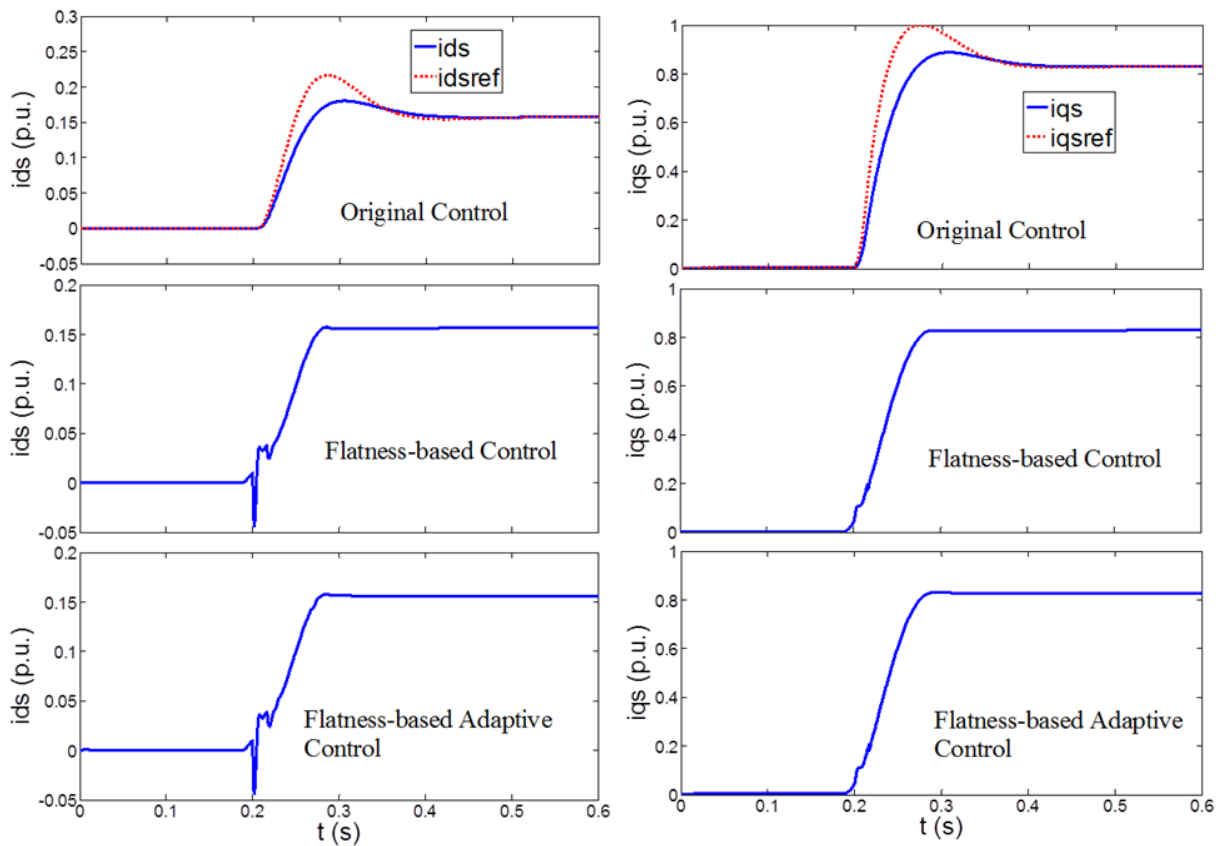

(a)

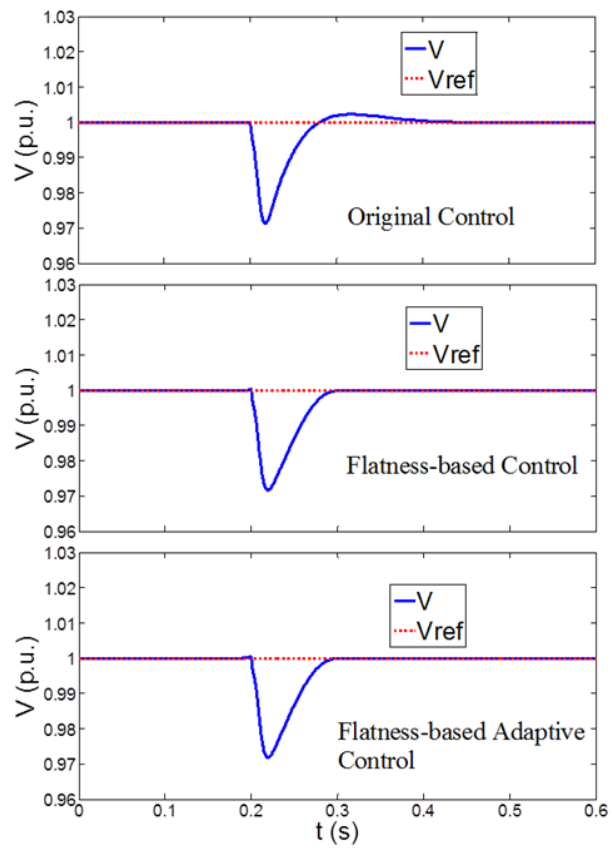

(c)

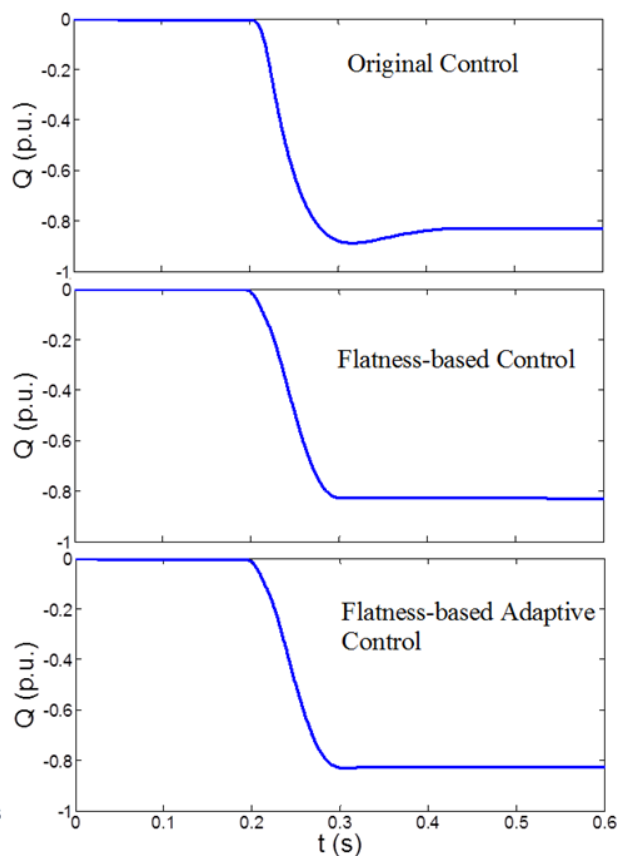

(d)

Figure 6: Results for change of reactive load 

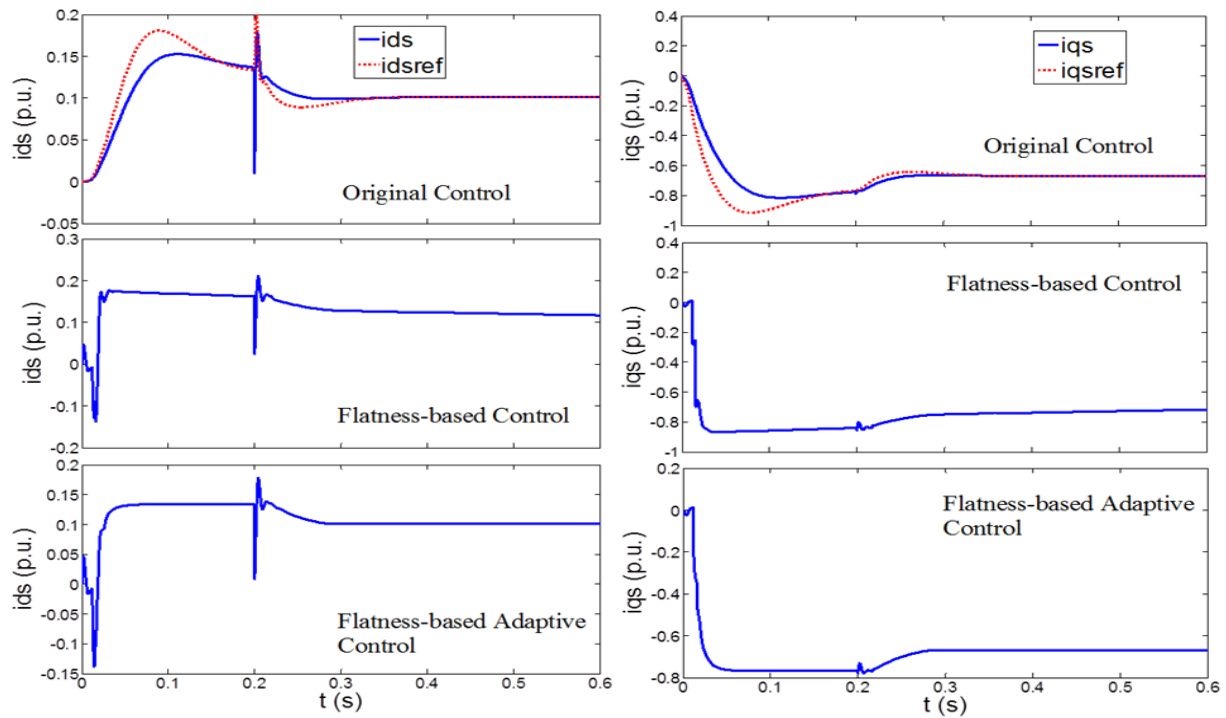

(a)
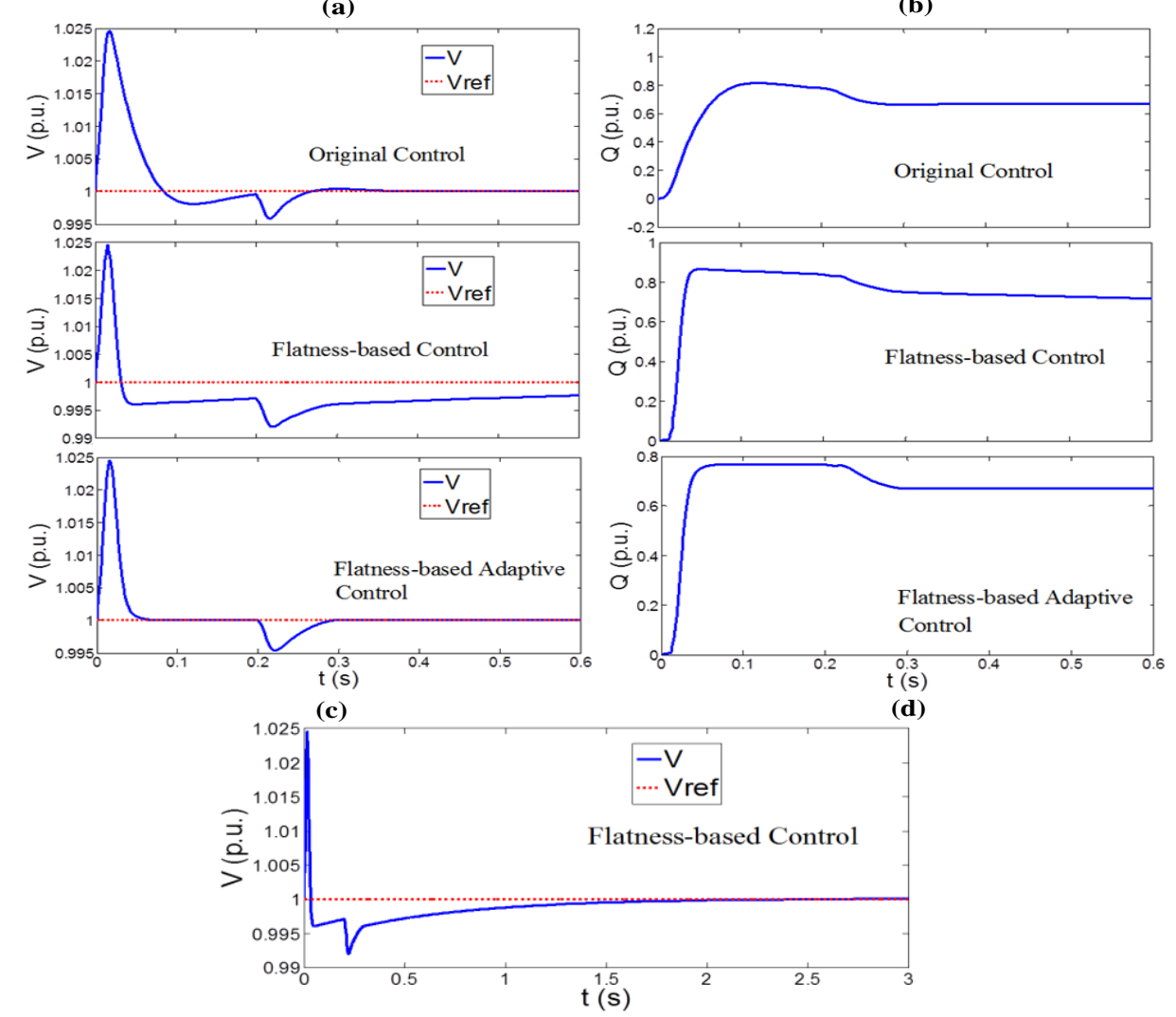

(e)

Figure 7: Results for change of transmission network 

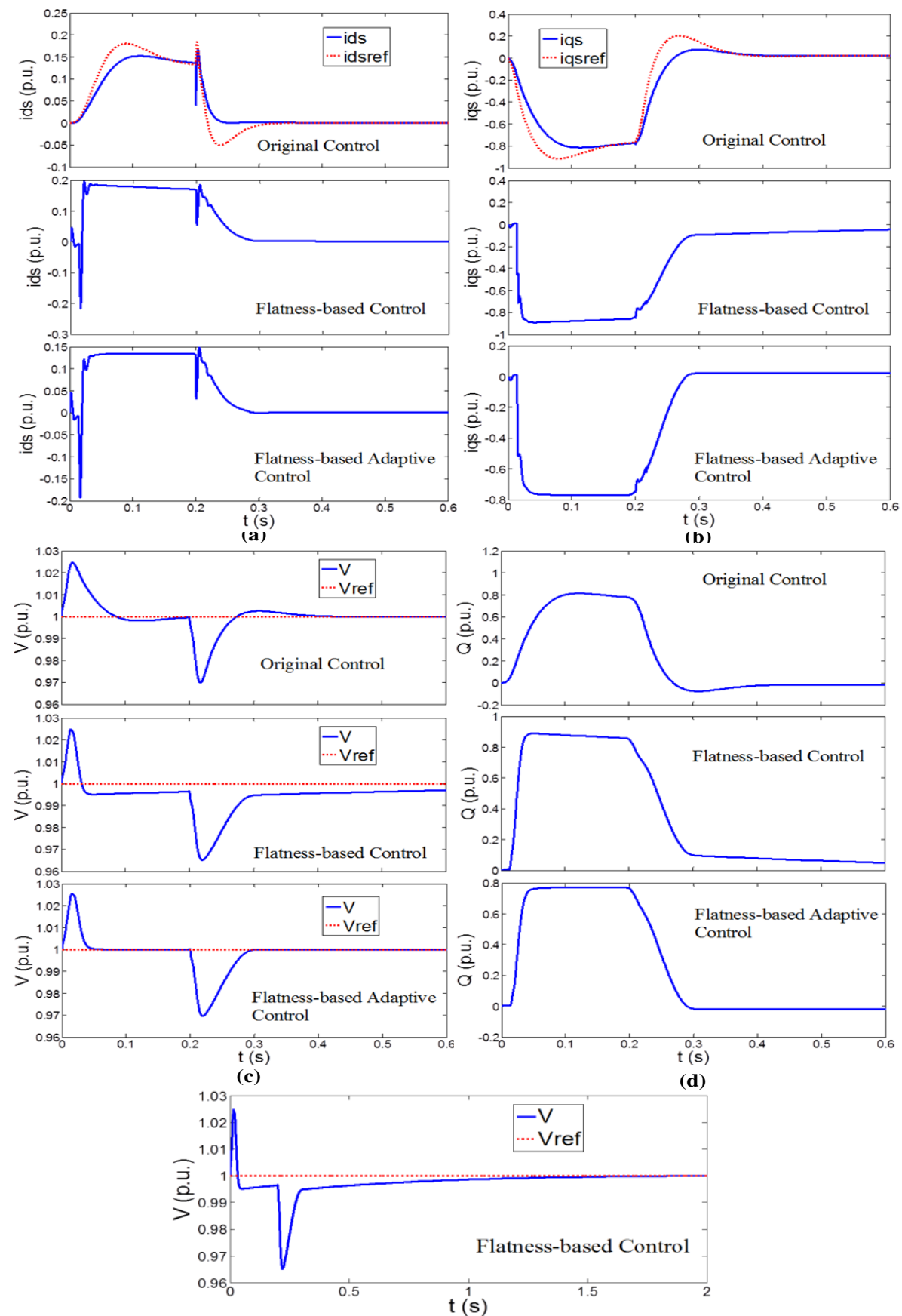

(e)

Figure 8: Results for change of transmission network and load 
Table 1: Performance comparison for change of reactive load.

\begin{tabular}{cccc}
\hline \hline & Original Ctrl. & $\begin{array}{c}\text { Flatness based Ctrl. } \\
\text { (FBC) }\end{array}$ & $\begin{array}{c}\text { Flatness based adaptive } \\
\text { Ctrl. (FBAC) }\end{array}$ \\
\hline \hline Lowest voltage after disturbance & $0.9713 \mathrm{p.u}$. & $0.9713 \mathrm{p.u}$. & 0.9713 p.u. \\
\hline Time $(\mathrm{sec})$ when $\mathrm{V}=1.0$ & $0.4293 \mathrm{sec}$ & $0.3001 \mathrm{sec}$ & $0.2895 \mathrm{sec}$ \\
\hline$\Delta$ t to reach $\mathrm{V}=1.0$ & $0.2293 \mathrm{sec}$ & $0.1001 \mathrm{sec}$ & $0.0895 \mathrm{sec}$ \\
\hline Var amount at steady state & -0.83 p.u. & $-0.83 \mathrm{p} . \mathrm{u}$. & -0.83 p.u. \\
\hline \hline
\end{tabular}

Table 2: Performance comparison for change of transmission network.

\begin{tabular}{cccc}
\hline \hline & Original Ctrl. & $\begin{array}{c}\text { Flatness based Ctrl. } \\
\text { (FBC) }\end{array}$ & $\begin{array}{c}\text { Flatness based adaptive } \\
\text { Ctrl. (FBAC) }\end{array}$ \\
\hline \hline $\begin{array}{c}\text { Highest voltage after change of } \\
\text { transmission network }\end{array}$ & 1.0245 & 1.0245 & 1.0245 \\
\hline $\begin{array}{c}\text { Time (sec) when V=1.0 after } \\
\text { change of transmission network }\end{array}$ & N/A & N/A & 0.0765 \\
\hline Lowest voltage after disturbance & 0.9955 p.u. & $0.992 \mathrm{p.u}$. & 0.9955 \\
\hline $\begin{array}{c}\text { Time (sec) when V=1.0 after } \\
\text { disturbance }\end{array}$ & $0.3824 \mathrm{sec}$ & 2.2863 & $0.2914 \mathrm{sec}$ \\
\hline $\begin{array}{c}\Delta \mathrm{t} \text { to reach } \mathrm{V}=1.0 \text { after } \\
\text { disturbance }\end{array}$ & $0.1824 \mathrm{sec}$ & 2.0863 & $0.0914 \mathrm{sec}$ \\
\hline Var amount at steady state & 0.67 p.u. & 0.67 p.u. & 0.67 p.u. \\
\hline \hline
\end{tabular}

Table 3: Performance comparison for change of transmission network and load.

\begin{tabular}{cccc}
\hline \hline & Original Ctrl. & $\begin{array}{c}\text { Flatness based } \\
\text { Ctrl. (FBC) }\end{array}$ & $\begin{array}{c}\text { Flatness based adaptive } \\
\text { Ctrl. (FBAC) }\end{array}$ \\
\hline \hline $\begin{array}{c}\text { Highest voltage after change of } \\
\text { transmission network }\end{array}$ & 1.0245 & 1.0245 & 1.0245 \\
\hline $\begin{array}{c}\text { Time (sec) when V=1.0 after change } \\
\text { of transmission network }\end{array}$ & $\mathrm{N} / \mathrm{A}$ & $\mathrm{N} / \mathrm{A}$ & 0.0619 \\
\hline Lowest Voltage after disturbance & $0.9698 \mathrm{p.u}$. & $0.9652 \mathrm{p.u}$. & $0.97 \mathrm{p.u}$. \\
\hline $\begin{array}{c}\text { Time (sec) when V=1.0 after } \\
\text { disturbance }\end{array}$ & $0.4166 \mathrm{sec}$ & 1.9082 & $0.3025 \mathrm{sec}$ \\
\hline$\Delta \mathrm{t}$ to reach V=1.0 after disturbance & $0.2166 \mathrm{sec}$ & 1.7082 & $0.1025 \mathrm{sec}$ \\
\hline Var amount at steady state & $-0.02 \mathrm{p.u}$. & $-0.02 \mathrm{p.u}$. & $-0.02 \mathrm{p.u}$. \\
\hline \hline
\end{tabular}

